\title{
The alarming implications of the internet of things
}

IoT gathers information from us in so many different ways that the limits to our privacy. During 1967, Alan Westin proposed that privacy was only a means of power over one's world to dictate where, how, and to the degree to which knowledge about it was transmitted to others, in an acclaimed book called Privacy and Freedom. The first example of this check was the walls that we created, so that people could not figure out what happened to our homes' privacy. In due course, this oversight was practiced through a variety of laws we passed, including our privacy rights as we shared sensitive information with our physicians and attorneys.

Under this light, privacy is nothing other than the method of controlling the limits of personal knowledge, such that certain people are often made available for a certain reason and some other time it is denied on the grounds of our own decision that the particular exposure relates to our needs. This means that certain individuals will be able to access the information for some reasons. Data privacy regulation provides the basis for these border controls, asking individuals that we are providing data to agree to prior to their processing to be clear about their activities-ensuring that their use of this information is restricted to the particular reason for which they have told us. However we have had an unparalleled tension late in the day when we were able to monitor the controls on our personal privacy. We are surrounded by smart devices that continually gather input from us, alter the essence and the power to monitor anything that passes through them.

The internet of matters (IoT) is a generalized term used to describe a broad variety of common devices upgraded to capture and analyze data that can be distributed via Internet network to remote data servers, in addition to their usual functions. These machines have proliferated to such a degree that they are among us now, gathering data from us in so many different ways that historically secure borders of our privacy have totally broken down. We have none but ourselves to blame all of the repercussions, because we were the ones who took these goods freely and consent to the terms and conditions of their use.

The results drawn from feedback obtained by multiple IoT devices are considerably more informative, however intrusive individual IoT devices can be. For example, wearable monitors can allow people to monitor their workout regimen, monitoring the heart rate and respirability, however they can show whether or not they are consuming cocaine, cigarettes, or alcohol whether they are being mixed. In conjunction with data obtained by speech recognition systems, facial recognition technology can produce a reliable analysis for emotion and feeling. The idea that these machines belong to us anywhere that we turn means that, if we had a private discussion, our right to control your privacy has been long gone by merely shutting the door.

Because most wired devices are common objects, we prefer to not regard them as data collectors and document what we say and do constantly. This suggests that we behave in their company more uninhibitedly than we will in the presence of strangers. Examples of our blatant misunderstanding of IoT devices and the data they gather are embodied in the various situations in which smart technology data
Volume 7 Issue I - 202 I

\author{
Pawan Whig \\ Dean Research,Vivekananda Institute of Professional Studies, \\ India
}

Correspondence: Dr. Pawan Whig, Senior IEEE Member, Dean Research, Vivekananda Institute of Professional Studies, New Delhi, India, Tel 98I 1908699, Email pawanwhig@gmail.com

Received: February 24, 2021 | Published: March I5, 2021

has been used as evidence of homeland privacy crimes. If it becomes the norm, the way we deal with our IoT devices is compelled to adjust. That said, in return for the many advantages provided by these devices, we also agree to retain the restricted freedom to monitor the limits of our personal room. Intelligent communities are full of sensors designed to capture, interpret and exchange information on traffic flows, use of energy and the citizens' waste management activities. All these details offer municipal managers an in-depth view into their individual lives. However, in order to enjoy the many advantages they provide, we embrace the reduced anonymity that comes with living in such cites. That said, in return for the many advantages provided by these devices, we also agree to retain the restricted freedom to monitor the limits of our personal room. Intelligent communities are full of sensors designed to capture, interpret and exchange information on traffic flows, use of energy and the citizens' waste management activities. All these details offer municipal managers an in-depth view into their individual lives. However, in order to enjoy the many advantages they provide, we embrace the reduced anonymity that comes with living in such cites. We need to amend our policies in order to better reflect the effect of IoT on our lives. If the computers and sensors that will capture our data in the future are too limited for us to have displays that will convey alerts and receive consent, so we shall need to identify alternatives for consent. More specifically, we will need to develop new leverage from which we can manage our personal room, and when IoT technologies start to be used against us, the results will be refreshing, as they will probably be, of this new method of continuous tracking.

\section{Funding}

None.

\section{Acknowledgments}

None.

\section{Conflicts of interest}

The author declares that there is no conflict of interest. 